\title{
Quantifying tiller re-growth of hybrid pennisetum canopies
}

\author{
M. Warndorff ${ }^{1}$, A. Dovrat ${ }^{1}$ and T. Kipnis ${ }^{2}$
}

1Faculty of Agriculture, Hebrew University, P.O. Box 12, Rehovot 76-100, Israel

${ }^{2}$ Volcani Centre, Agricultural Research Organization, P.O. Box 6, Beit Dagan, Israel

Received 5 June 1985; accepted 18 September 1985

Key-words: Pennisetum americanum $\times P$. purpureum, defoliation, morphology, computer simulation

\section{Summary}

Analysis of the dynamics of tiller production by means of a simple descriptive simulation model enabled reasonable prediction of the productivity of the bunch-grass hybrid pennisetum subjected to different defoliation treatments. The re-growth capability of tillers depended on the apical distance (i.e. the distance between the ligule of the last fully expanded leaf and the apical meristem), the cutting height and the distribution of tiller lengths. The initial rate of re-growth of intact tillers depended on the amount of residual leaf mass left as stubble on the field, whereas new tiller growth from decapitated tillers depended on the number of basal adventitious buds and the development of lateral tillers, the latter determined by the number of leaves produced on the main stem. Growth was monitored through a simple function of irradiance, temperature and light extinction in the canopy, the latter analysed in terms of tiller length distribution. Under optimal growth conditions, with respect to water and nutrient supply, the maximum crop growth rate of the canopy was approximately $300 \mathrm{~kg} \mathrm{ha}^{-1} \mathrm{~d}^{-1}$. The delay in the immediate re-growth of a 6-week old canopy caused its dry matter yield after 6 weeks of growth to be similar to the total yields obtained from 2 cycles of growth from canopies cut at intervals of 3 weeks each.

\section{Introduction}

In the management of tropical tallgrasses, such as hybrid pennisetum (Pennisetum americanum $\times P$. purpureum), the length of the time interval between cuttings (or grazings) decisively determines the amount, the quality or both of the harvested forage. This sensitivity to periodic defoliation is mainly caused by the relatively early stage of growth at which internode elongation of the tillers occurs in these grasses (Booysen et al., 1963; Dirven, 1970). The resulting rapid stem formation is conducive to a relatively low digestibility of the forage on the one hand, and to a delay in 
re-growth after defoliation on the other hand (Muldoon \& Pearson, 1979b). However, little is known about the quantitative aspects of re-growth of tallgrass canopies subjected to different cutting frequencies. In an earlier communication (Dayan et al., 1981) details are reported on a model named TILDYN which simulates the re-growth of sward-forming Rhodes grass (Chloris gayana Kunth) through the simultaneous calculation of the number and weight of tillers and their classification into classes differing from each other in capability of re-growth.

The purpose of this study was to define and quantify morphological parameters related to the re-growth of hybrid pennisetum and to evaluate a descriptive simulation model developed on the basis of these parameters.

\section{Materials and methods}

Plants of hybrid pennisetum (Pennisetum americanum $\mathrm{cv}$. Tift $23 \mathrm{~A} \times P$. purpureum $\mathrm{cv}$. N23) were used in this study. Observations and measurements were made of tillers grown in pots in the greenhouse or of tillers from plants growing in the field. The nomenclature of basic morphology is that of Muldoon \& Pearson (1979b).

\section{Morphology of re-growth}

Apical distance. Tillers varying in length from 18 to $80 \mathrm{~cm}$, were selected at random in the field of a 5-week old well-developed canopy. They were cut at soil level and the length of each was measured from the cut surface to the top ligule (i.e. of the youngest fully expanded leaf). Afterwards each tiller was halved longitudinally with a sharp knife-blade in order to detect the location of the apical meristem. The distance measured between the apical meristem and the top ligule is referred to as 'apical distance'.

Classification of tillers. Rooted tillers, representing a wide range of tiller lengths, were separated from a number of fully grown plants and placed in water during 2 days for promoting further root development. Thirty-six of the well-rooted tillers were defoliated at $6 \mathrm{~cm}$ above the root crown and placed in $250-\mathrm{ml}$ containers filled with vermiculite and regularly watered with a complete nutrient solution. After 14 days of undisturbed growth the re-growth of the tillers was recorded in terms of:

(1) Tillers from which the apical meristem was not removed or damaged following defoliation, and that continued to produce new leaves. These are referred to as 'intact' tillers.

(2) Tillers from which the apical meristem was removed following defoliation of the main stem. These are referred to as 'decapitated' tillers.

(3) New tillers arising from basal adventitious buds.

(4) 'Lateral tillers' are those which arise from the axils of leaves.

Residual tiller weight. Tillers varying in length from 6 to $110 \mathrm{~cm}$ were selected at random in the field when the canopy was 3 and 6 weeks old, respectively. Each tiller was cut at soil level and divided into 2 fractions: (a) the basal part measuring $10 \mathrm{~cm}$ 
long and (b) the remainder. Both fractions were dried at $70{ }^{\circ} \mathrm{C}$ in a forced-air oven until constant weight. The weight of the basal fraction is termed 'residual tiller weight'.

\section{Field experiment}

In the summer of 1983 aerial tillers separated by hand from mature stems were planted in the field at the experimental farm of the Volcani Centre at Beit Dagan. The experiment was of a block design with 6 blocks (replicates) each measuring $12 \mathrm{~m} \times 12 \mathrm{~m}$. Two treatments were imposed: cutting intervals of 3 weeks or of 6 weeks during a period of 130 days. Each plot measured $6 \mathrm{~m} \times 12 \mathrm{~m}$. Plants were spaced at $60 \mathrm{~cm} \times 60 \mathrm{~cm}$, but approximately $15 \%$ of the plants did not survive the winter, so that the density was about 24000 plants per ha.

The field was sprinkler-irrigated once a week at night at a rate of $7 \mathrm{~mm} \mathrm{~d}^{-1}$ (approximately $80 \%$ of the Class A pan evaporation rate). Previous irrigation experiments with this grass in the same field showed that this amount amply meets its water requirements.

$\mathrm{P}$ (as superphosphate) and $\mathrm{K}$ (as potassium chloride) were applied at the start of the experiment (summer 1984) at the rate of 48 and $145 \mathrm{~kg} \mathrm{ha}^{-1}$, respectively. $\mathrm{N}$ (as ammonium sulphate) was added before each irrigation at $35 \mathrm{~kg} \mathrm{ha}^{-1}$ and hand-distributed.

The cutting treatments started on 10 May 1984 (with a cleaning cut of all plots) and terminated 17 September. During that period 6 cuttings were carried out at 3week intervals $(31 / 5,25 / 6,16 / 7,6 / 8,27 / 8,17 / 9)$, and 3 cuttings at 6 -week intervals $(25 / 6,6 / 8,17 / 9)$.

Every 10 days one plant randomly chosen was harvested from each plot, weighed green, and the total number of tillers counted. Approximately one-third of the plants was taken for determining the percentage of dry matter. The remaining twothirds were used to determine the tiller length distribution as follows:

1. The length of each tiller was measured from the cutting level to the top ligule (i.e. the youngest fully expanded leaf).

2. The tillers were then graded according to their length into 4 size groups: less than $10 \mathrm{~cm}$ long, from 10 to $20 \mathrm{~cm}$, from 20 to $40 \mathrm{~cm}$, and longer than $40 \mathrm{~cm}$.

3. For each size group the following was recorded: (a) number of intact tillers, (b) number of decapitated tillers, and (c) number of dead tillers, i.e. those of which the youngest leaf was dead, which indicates the lack of apical activity (Langer, 1956).

The difference between the total number of tillers and the number of 'dead' tillers is termed the number of 'live' tillers, and is used for comparison with the simulated tiller number, which consists of live tillers only.

\section{Modelling aspects}

The model was developed to simulate the course of dry matter production of a grass canopy from the simultaneous changes in number and weight of its tillers. The mod$\mathrm{el}$ is based on concepts developed in a model named TILDYN which was validated 
with Rhodes grass (Dayan et al., 1981). The programme is written in Basic-Plus of the Digital PDP-11*.

\section{Tiller classes}

The total number of tillers in the canopy was divided into classes - each $5 \mathrm{~cm}$ length defined as a separate class - representing different developmental stages. Tiller length was chosen as a classifying parameter so as to facilitate comparison with the results of the field experiment (for validation of the model), being easy to measure yet accurate in comparison to other parameters such as leaf number or tiller weight.

Tiller growth and development, however, proceeded on the basis of tiller weight. A close relationship was found between the tiller weight $(W)$ and its length (L), from which the specific average and maximum weight was defined for each tiller class:

$$
\ln (\mathrm{W})=-5.70+1.96 \times \ln (\mathrm{L})\left(r^{2}=0.95, n=34\right)
$$

When, due to tiller growth, the mean weight of the tillers in a particular class exceeded the specified average weight, a quarter of the tillers (the heaviest) were moved to the next higher class. When it exceeded the specified maximum weight, the entire number of tillers was transferred to the next higher class.

\section{Tiller re-growth}

Tiller re-growth is first and foremost dependent on whether its apical meristem is removed (or damaged) with cutting. This is considered a function of three parameters: the length of the tiller, the location of the apical meristem within the tiller, and the height of defoliation. It was found that the apical meristem is located at an almost constant $19.3 \pm 0.4 \mathrm{~cm}$ measured from the top ligule. A tiller is decapitated when its length is greater than the sum of the apical distance plus the cutting height.

Since in our field experiment the cutting height was $10 \mathrm{~cm}$ above the soil surface and the apical distance was approximately $20 \mathrm{~cm}$, any tiller taller than $30 \mathrm{~cm}$ is considered to be decapitated after defoliation. However, extensive observations of tillers growing in pots and in the field showed that tillers which were not decapitated but defoliated just above the apical meristem were also not capable to continue leaf extension - probably due to the exposure of the apical meristem after the loss of the protective leaves and sheaths. Thus tillers from 25 to $30 \mathrm{~cm}$ tall are also considered to be decapitated as a result of defoliation.

Intact tillers initiate their re-growth from the residual tiller material. The regression of residual tiller weight (RW) on total tiller weight $(\mathrm{W})$ was determined experimentally:

$$
\ln (\mathrm{RW})=-0.34+0.634 \times \ln (\mathrm{W})\left(r^{2}=0.96, n=33\right)
$$

\footnotetext{
${ }^{*}$ The full text of the programme is available from the authors upon request.
} 
Tillers whose apical meristem was removed at defoliation are dependent for regrowth on the development of basal adventitious buds into new tillers. The average number of basal buds per decapitated tiller producing new tillers was $3.6 \pm 0.2$, irrespective of the length of the main stem. New tillers did not appear instantaneously, but their appearance was spread over a period of approximately 10-14 days. In the model, the total number of decapitated tillers is multiplied by 3.5 to obtain the total number of potential new tillers. The first day after defoliation a fraction (1/5) of these buds are transferred into the smallest tiller class, where they start with an initial weight of $0.08 \mathrm{~g}$ per tiller (an estimate). Each subsequent day the same fraction of the remaining basal buds is similarly transferred. By the 10th day after defoliation $90 \%$ of the buds have 'developed' into tillers.

\section{Tiller growth}

The growth of tillers is dependent on the average daily temperature, the total daily radiation received, and on the weight of the photosynthetic tissue, assuming water and minerals are not limiting growth. All tillers in a given class contribute the same growth rate.

For each day the average daily temperature is taken from current readings and the total daily radiation from long-term averages. Tillers in the tallest class receive full light while the shorter tillers receive proportionally less light depending on the leaf area index and on the extinction coefficient calculated according to the formula of Monsi \& Saeki (1953). The extinction coefficient used equals 0.5, an average value from different grasses.

From the average daily temperature and radiation reaching each tiller, its relative growth rate (RGR) is calculated with an equation experimentally derived for hybrid pennisetum by Muldoon (1979). This is multiplied by the weight of the photosynthetic tissue (leaf blades and sheaths only) in order to obtain the daily growth increment. The regression of leaf-blade weight (LW) on total tiller weight (W) is characterized by a quadratic regression:

$$
\ln (\mathrm{LW})=-0.22+0.85 \ln (\mathrm{W})-0.023 \times(\ln (\mathrm{W}))^{2}\left(r^{2}=0.99, n=98\right)
$$

The weight of sheaths was estimated to be equal to $20 \%$ of the leaf blade weight.

The leaf area per tiller is calculated by multiplying the leaf weight by the specific leaf area (SLA) which was determined experimentally. SLA decreases as the tiller increases in length. The leaf area is summed for all the tillers in each class to obtain the partial leaf area index for each class separately. The irradiance reaching any one particular class is determined by summing the partial leaf area indices of all the tiller classes taller than itself and substituting the value obtained into the light extinction formula.

As the weight of the canopy increases, the amount of light reaching the lower tiller classes decreases, and consequently the RGR as well. When the calculated RGR is less than $0.02 \mathrm{~g} \mathrm{~g}^{-1} \mathrm{~d}^{-1}$ (an estimate) tiller death is assumed to occur. This is achieved by removing one tenth (an estimate) of the tiller number (and weight) of each class for which the RGR reaches this value. 


\section{Lateral tillering}

In addition to tillers initiated from basal buds following defoliation, new tillers are produced as a result of lateral tillering. It was found that only tillers between 10 and $20 \mathrm{~cm}$ long produce lateral tillers. Those shorter did not yet reach the minimal size required, while those taller already started internode elongation which causes depression of lateral tiller production most probably due to apical dominance.

The rate of lateral tiller production is limited by the rate of leaf production which in turn is determined by temperature (Muldoon \& Pearson, 1979a). It is assumed that for each leaf one lateral tiller is produced with an initial weight of $0.08 \mathrm{~g}$.

Production of lateral tillers, as the development of basal buds, is halted when the RGR is below the value required for their maintenance $\left(0.02 \mathrm{~g} \mathrm{~g}^{-1} \mathrm{~d}^{-1}\right)$.

\section{Defoliation}

Part of each tiller remains as stubble on the field as the residual tiller weight. The yield is the sum of the forage removed from all the tillers in the canopy upon cutting.

\section{Model validation}

The course of dry matter accumulation after cutting generally started with an initial period of slow re-growth followed by a period of quick linear growth (Fig. 1A, C). However the rate of initial re-growth after 6 weeks of growth was almost 4 times slower than after 3 weeks of growth. On the other hand the rate of quick linear growth was quite similar for both cutting cycles. There was good agreement between the courses of measured and simulated dry matter.

The increase in number of tillers during the 3 weeks of growth usually proceeded
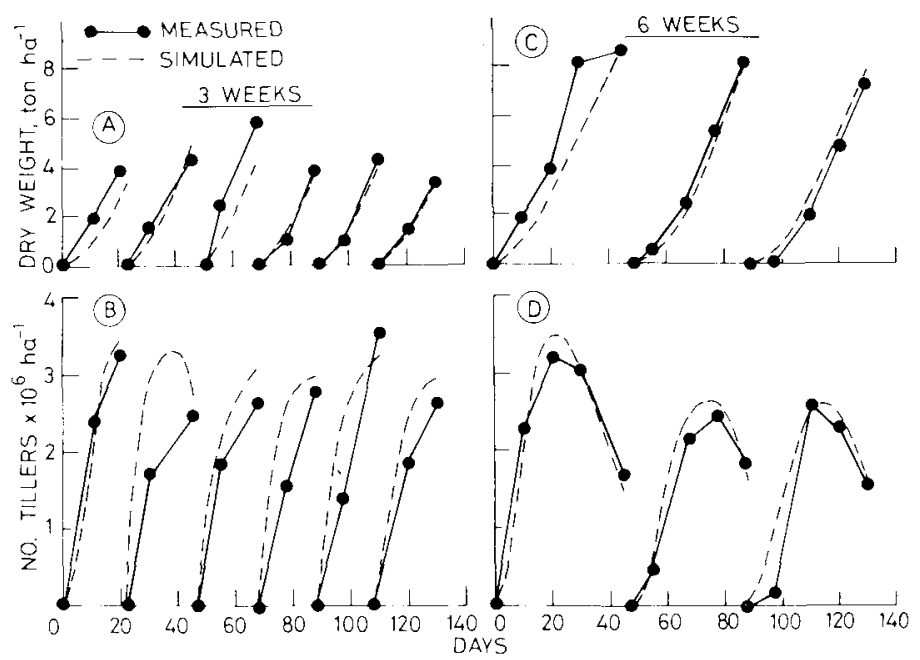

Fig. 1. Measured and simulated dry matter accumulation and number of tillers following cutting intervals of 3 weeks (A, B) or 6 weeks (C, D) of hybrid pennisetum. 
Table 1. Measured and simulated number of tillers, weight per tiller, percentage decapitated and dead tillers of different length classes at the end of the cutting interval. Means of six 3-week and three 6-week intervals.

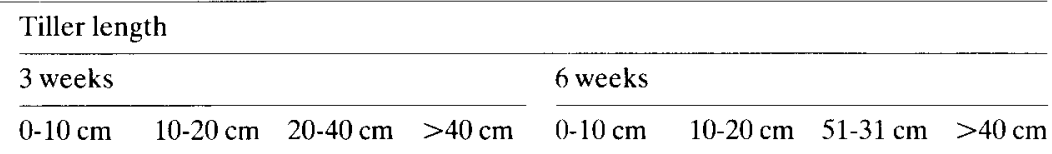

\begin{tabular}{lllllllll}
$\begin{array}{l}\text { Number of } \\
\text { tillers per } \mathrm{m}^{2}\end{array}$ & & & & & & & & \\
$\quad \begin{array}{l}\text { Measured } \\
\text { Simulated }\end{array}$ & $177(63)^{1}$ & $83(29)$ & $23(8)$ & - & $24(15)$ & $28(17)$ & $51(31)$ & $61(37)$ \\
$\begin{array}{l}\text { Weight per } \\
\text { tiller }(\mathrm{g})\end{array}$ & 0.16 & 1.69 & 2.93 & - & 0.53 & 1.30 & 3.48 & 7.73 \\
$\begin{array}{l}\text { Decapitated } \\
(\%)\end{array}$ & 0 & 15 & 91 & - & 0 & 0 & 78 & 100 \\
Dead $(\%)$ & 3 & 0 & 0 & - & 70 & 48 & 1 & 0 \\
\hline
\end{tabular}

1 Percentage of total.

at a uniform rate; however the simulated tiller production generally overestimated the measured tiller production (Fig. 1B). In the 6-week treatment the number of tillers at day 10 was approximately 6 times less than in the 3 -week treatment. During the 6-week period of growth the measured number of tillers was similar to the simulated number of tillers (Fig. 1D). Furthermore it should be noted that during the 6-week period of growth a decrease in the total number of tillers occurred (which started around day 25) with a net result of the loss of approximately $40 \%$ of the tillers, which apparently died because of the lack of light required for their development.

As expected, the distribution of tiller lengths after 3 weeks was very different from the 6 weeks of re-growth (Table 1). At the end of the 3-week period more than $90 \%$ of the tillers were less than $20 \mathrm{~cm}$ long (above cutting height), most of them intact. In contrast, after 6 weeks of re-growth almost $70 \%$ of the tillers were longer than $20 \mathrm{~cm}$ and thus were mostly decapitated upon defoliation. Additionally a high proportion of dead small tillers was found.

The average measured and simulated dry matter yields of the 3-week cutting frequency were $423( \pm 55)$ and $375 \mathrm{~g} \mathrm{~m}^{-2}$ respectively, and of the 6-week cutting frequency $801( \pm 171)$ and $821 \mathrm{~g} \mathrm{~m}^{-2}$ respectively. Since climatic conditions during the season were quite uniform only small differences were found between yields obtained after cutting at identical intervals.

A significant finding is that the total dry matter yield of 2 cuttings of 3-week cycles each, was similar to the yield obtained after one cycle of 6 weeks.

\section{Discussion}

The pattern of production of hybrid pennisetum largely reflects the weather pattern 
(Muldoon, 1979) and the transition from the vegetative to the stem-elongation phase of growth.

When defoliated, a rapid increase in shoot occurs during re-growth; however, the initial rate of re-growth is affected by the fate of the apical meristem. If the apical meristem remains intact leaf production continues, but if the meristem is removed then lateral tillering is necessary before leaf production resumes, resulting in initially slower re-growth (Muldoon \& Pearson, 1979b). Thus, if climatic and other growth conditions are optimal, the rate of initial dry matter accumulation depends on the number and morphological structure of the tillers which remain on the stubble after defoliation. Analysis of the morphological structure of hybrid pennisetum is facilitated by their size. However, the tillering mechanism of tropical grasses is hardly investigated.

Apical distance (i.e. the distance measured between the top ligule and the apical meristem) in the elongated vegetative tiller was found to be constant irrespective of tiller length at least during 6 weeks of growth. The apical distance of field-grown plants of hybrid pennisetum reported by Muldoon \& Pearson (1977) was only slightly less than that found in this study. There are indications (unpublished results) that this distance is affected by the variety and possibly also by growing conditions. The apical distance measured in the male parent of the hybrid was considerably greater than in the hybrid.

The re-growth capability of a hybrid pennisetum canopy therefore could conveniently be predicted from the apical distance, the distribution of tiller lengths and the cutting height, although the latter was not pursued experimentally.

The initial rate of re-growth of decapitated tillers was found to be dependent on the number of developing basal adventitious tillers, which was 3-4, irrespective of the length of the main stem in hybrid pennisetum. However, Mitchell (1953) reported that the longer the development of basal buds was inhibited in ryegrass, the more time elapsed until they started to develop into tillers. Cutting intervals longer than 6 weeks, therefore, may give rise to a smaller number of basal buds to develop; however, this was not investigated. The development of basal buds also seems to be genetically determined. For example decapitated tillers of pearl millet were found to re-grow with difficulty, due to the inability of the basal adventitious buds to develop (Begg, 1965).

The initial re-growth of intact tillers was assumed to be dependent on the weight of the tiller residue (Jewiss, 1972), a parameter which was found to be linearly related to the total tiller weight.

The development of lateral tillers in hybrid pennisetum, as reported by Pearson (1975), did not start before 6 leaves had been produced. This, in our model, was estimated to occur after the tiller was at least $10 \mathrm{~cm}$ long (from the soil surface). The number of lateral tillers equals the number of leaves produced under optimal growth conditions (Youngner et al., 1976), but is halted when the main stem starts to elongate (probably due to the production of inhibitory levels of auxin according to Jewiss (1972) and Clifford (1977)). In the model this was assumed to occur when the main stem was longer than $20 \mathrm{~cm}$. The production of lateral tillers is halted also when the light intensity reaching the lowest tiller class is below that required for 
their maintenance (Mitchell, 1953), in the model expressed on the basis of the relative growth rate.

Tiller density/weight relationships are complex and were not explored in this study. This relationship involves factors such as apical dominance, light penetration and possibly physiological and/or genetic limitations in the maximum number of tillers individual plants are able to support. The latter limitations most probably had no effect in our study. At a density of $50 \mathrm{~cm} \times 50 \mathrm{~cm}$ between hybrid pennisetum plants, similar to the one used in this study, it was found by Pearson \& Anthony (1977) that the number of tillers per plant was not a limiting factor for attaining maximum dry matter accumulation; however, at the $100 \mathrm{~cm} \times 100 \mathrm{~cm}$ planting density, they found that the number of tillers per $\mathrm{m}^{2}$ was lower than at the $50 \mathrm{~cm} \times 50$ $\mathrm{cm}$ density, which resulted in lower dry matter accumulation.

Three-week old canopies, irrespective of the length of the pre-cutting period, were found to have a similar tiller density, though different in tiller length distributions. When the canopy was left to grow longer than 3 weeks, death of young tillers occurred, probably due to the more successfull competition for light and greater access to assimilates of large tillers than of relatively small tillers (Ong, 1978; Shih \& Gascho, 1980).

In conclusion, our studies indicate that the guiding principles developed for the TILDYN model, which were validated with data from the re-growth of swardforming Rhodes grass (Dayan et al., 1981), can succesfully be applied in the simulation of the re-growth of the erect bunch grass hybrid pennisetum. Both studies draw attention to the importance of elucidating factors affecting the re-growth mechanism of individual tillers and their expression as major factors in yield formation of grass canopies subjected to defoliation. Forage quality aspects will be the subject of a later communication.

\section{Acknowledgement}

This research project was supported by a grant from the US-Israel Agricultural Research and Development Fund (BARD).

\section{References}

Begg, J. E., 1965. The growth and development of a crop of bulrush millet (Pennisetum typhoides S. H.). Journal of Agricultural Science, Cambridge 65: 341-349.

Booysen, P. de V., N. M. Tainton \& J. D. Scott, 1963. Shoot-apex development in grasses and its importance in grassland management. Herbage Abstracts 4: 209-213.

Clifford, P. E., 1977. Tiller bud suppression in reproductive plants of Lolium multiflorum Lam. cv. Westerwoldicum. Annals of Botany 41: 605-615.

Dayan, E., H. van Keulen \& A. Dovrat, 1981. Tiller dynamics and growth of Rhodes grass after defoliation: A model named TILDYN. Agro-Ecosystems 7: 101-112.

Dirven, J. G. P., 1970. Die Aufgabe der Gräserzüchtung in den Tropen unter besonderer Berücksichtigung von Vermehrung, Ertrag und Futterwert. Zeitschrift für Kulturtechnik und Flurbereinigung 11: 92-107.

Jewiss, O. R., 1972. Tillering in grasses - Its significance and control. Journal of the British Grassland Society 27: 65-82. 


\section{WARNDORFF, A. DOVRAT AND T. KIPNIS}

Langer, R. H. M., 1956. Growth and nutrition of timothy, Phleum pratense. 1 . The life history of individual tillers. Annals of Applied Biology 44: 166-187.

Mitchell, K. J., 1953. Influence of light and temperature on the growth of ryegrass, Lolium spp. 2 . The control of lateral bud development. Physiologia Plantarum 6: 425-443.

Monsi, M. \& T. Saeki, 1953. Über den Lichtfaktor in den Pflanzengesellschaften und seine Bedeutung für die Stoffproduktion. Journal of Japanese Botany 14: 22-52.

Muldoon, D. K., 1979. Simulation of hybrid pennisetum production in Australia. Agricultural Systems 4: 39-47.

Muldoon, D. K. \& C. J. Pearson, 1977. Hybrid pennisetum in a warm temperate climate: Regrowth and standover forage production. Australian Journal of Experimental Agriculture and Animal Husbandry 17: $277-282$.

Muldoon, D. K. \& C. J. Pearson, 1979a. Primary growth and regrowth of the tropical tallgrass hybrid pennisetum at different temperatures. Annals of Botany 43: 709-717.

Muldoon, D. K. \& C. J. Pearson, 1979b. Morphology and physiology of regrowth of the tropical tallgrass hybrid pennisetum. Annals of Botany 43: 719-728.

Ong, C. K., 1978. The physiology of tiller death in grasses. I. The influence of tiller age, size and position. Journal of the British Grassland Society 33: 197-203.

Pearson, C. J., 1975. Thermal adaptation of pennisetum: Seedling development. Australian Journal of Plant Physiology 2: 413-424.

Pearson, C. J. \& D. T. W. Anthony, 1977. Hybrid pennisetum in a warm temperate climate: Effects of plant density on summer production. Australian Journal of Experimental Agriculture and Animal Husbandry 17: 284-289.

Shih, S. F. \& G. J. Gascho, 1980. Relationships among stalk length, leaf area and dry biomass of sugarcane. Agronomy Journal 72: 309-313.

Youngner, V. B., F. Nudge \& R. Ackerson, 1976. Growth of Kentucky bluegrass leaves and tillers with and without defoliation. Crop Science 16: 110-113. 